\title{
Eastern Arc Mountains in Tanzania: Hic sunt Aenictopecheidae. The first genus and species of Afrotropical Aenictopecheidae (Hemiptera: Heteroptera: Enicocephalomorpha)
}

\author{
PAVEL ŠTYS ${ }^{1}$ and PETR BAŇǍr ${ }^{2}$ \\ ${ }^{1}$ Charles University in Prague, Faculty of Science, Department of Zoology, Viničná 7, CZ-128 44 Praha 2, Czech Republic; \\ e-mail: pavelstys@gmail.com \\ ${ }^{2}$ Moravian Museum, Department of Entomology, Hviezdoslavova 29a, CZ-627 00 Brno, Czech Republic; \\ e-mail: petrbanar@seznam.cz
}

Key words. Hemiptera, Heteroptera, Enicocephalomorpha, Aenictopecheidae, Ulugurocoris grebennikovi gen. n. et sp. n., taxonomy, morphology, epimeroid (new term), true bug, Afrotropical region, Tanzania, Eastern Arc Mountains, distribution

\begin{abstract}
A new genus and species of Hemiptera: Heteroptera: Enicocephalomorpha: Aenictopecheidae: Aenictopecheinae, Ulugurocoris grebennikovi gen. et sp. n., based on micropterous females from Tanzania, Uluguru Mts, Budunki, is described and differentiated. The males are probably macropterous. Some general aspects of morphology of $U$. grebennikovi are discussed in a broader context, such as presence of cephalic trichobothria (suggested to be a groundplan character of Heteroptera), presence of "gular sulci" (suggested to have an ecdysial function), lack of cephalic neck (symplesiomorphy with other Hemiptera), presence of posterior lobe of pronotum associated with the epimeroid (a new term for so called "proepimeral lobe"), and presence of notopleural sulcus on the propleuron. Diagnostic characters of the Aenictopecheinae are summarized and distribution of their seven genera is reviewed. Ulugurocoris grebennikovi is the first representative of the basal family Aenictopecheidae in the Afrotropical Region. The type locality is situated in the Eastern Arc Mountains (Tanzania), a recently identified hotspot of Afrotropical diversity characterized by a high degree of endemism caused by high rates of speciation combined with low rates of extinction. A brief characterization of the area is provided.
\end{abstract}

\section{INTRODUCTION}

The Aenictopecheidae (Enicocephalomorpha), Thaumastocoridae (Cimicomorpha) and Colobathristidae (Pentatomomorpha) are essentially pantropical families of Heteroptera but none of them has been recorded from the Afrotropical Region. Since the aenictopecheids do occur on Madagascar (in contrast to the latter two families) their occurrence in Afrotropis could be expected. However, in spite of extensive material of African Heteroptera accumulated in collections over the decades and numerous expeditions undertaken, the first Afrotropical aenictopecheids turned up only recently. Their discovery has been made possible owing to increased attention paid to the understudied forest litter fauna and by exploration of the only recently identified hotspot of Afrotropical diversity - the inland mountain islands of the East Arc Mountains in Kenya and Tanzania.

In this paper we provide a description of the new genus and species with much new data important to the morphology of Heteroptera. We also provide a comparison with other aenictopecheids, comment upon some features of general importance, and make general observations on the classification and distribution of the family.

We keep the comparative part simple since more data (particularly concerning the terminalia of both sexes, pterygopolymorphism and larvae) and a new key to aenictopecheine genera will be included in a study of newly discovered taxa from the Oriental and Madagascan regions (Baňař \& Štys, unpubl.).

\section{MATERIAL AND METHODS}

Under the term "dorsal ocular index" we understand the ratio minimum width of vertex to maximum width of eye; it is easiest when measured as 2 times minimum interocular distance / (maximum width across eyes minus minimum interocular distance).

Only the measurements of the holotype were taken, the paratype has been dissected.

The material was preserved in alcohol, abdomen of the paratype female was accidentally damaged by over-clearing and could not be used for a detailed study.

The label data are cited verbatim, including potential errors, using a slash (/) to separate rows on one label.

Colour photographs were made by Leica MSV266. Drawings were made using a SZP 11 ZOOM stereoscopic microscope, abdomen was studied using Olympus BX 41 microscope.

Most structural data are included in the generic description (and/or detailed in Discussion), while those likely to be of species-specific importance in a description of species only. Descriptions of the lateral and ventral walls of pterothorax are tentative owing to the bad visibility and minute size of the parts concerned. Some body regions could not be examined owing to a paucity of material (such as metapostcoxal frame, ventrites I and II). 


\section{TAXONOMY}

\section{Ulugurocoris gen. $\mathbf{n}$.}

(Figs 1-21)

Type species: Ulugurocoris grebennikovi sp. n., by present designation.

\section{Description (micropterous females)}

Small-sized (less than $4 \mathrm{~mm}$ ), micropterous, body parallel-sided but stout and robust (Figs 1-2).

Body with long, semi-erect to erect setae; dorsum of head, labium, pronotum and all legs with numerous outstanding, long trichobothrium-like setae.

Head (Figs 4-5, 7) robust and wide, postocular constriction distinct, shallow, present on the dorsum only. Eyes medium sized, in lateral view high and short, far distant both from strongly convex dorsal epicranial outline of head as well as from its ventral margin; distance anterior margin of eye-apex of antennifer subequal to eye length. Antennifer short, prominent. Ocular sulci distinct (Figs 4-5), extremely close to eye, encircling its entire perimeter, associated with paired gular sulci (Figs 4, 7) (see Discussion). Posterior lobe of head transverse, about twice as long as wide. A distinct neck absent. Ocelli fully developed, prominent in lateral view, closer to the lateral margin of posterior lobe of head than to each other. Three pairs of trichobothria present: 1+1 basi-anteclypeal, 1+1 epicranial (anterior interocular), $1+1$ postocellar.

Antennae longer than head and pronotum together, antennal formula (longest segment first) IV : III : II : I; flagellomeres (III and IV) thinner than scape and pedicel, but not flagelliform. Labium robust, short and broad, directed anterad, segments I and II ring-shaped, labial formula (longest segment first) III : IV : II : I.; dorsal side of segment II with $1+1$ trichobothria, of III with $3+3$ arranged in a line.

Prothorax (Figs 4-5, 7-8). Pronotum short and wide, its anterior margin straight, posterior margin slightly convex, distal parts of lateral margins straight. Collum rather long, well delimited on the notum by postcollar sulcus, laterally distinct up to the notopleural sulcus, more ventrally fused with precoxale and prosternum. Middle lobe simple, with inconspicuous, short linear medial impression, and slightly overhanging laterad, down to the notopleural sulcus. Posterior lobe present as a narrow, not externally delimited strip (posterolateral angles nearly rectangular), turning laterad far beneath the level of notopleural sulcus and forming there a seeming posterior part of proepimeron (see Discussion).

Notopleural sulcus running horizontally from collum over precoxale and proepisternum and proepimeron, nearly to posterolateral margin of prothorax, terminating at the site where proepimeron merges with the lateral part of "proepimeral lobe".

Propleuron minute, consisting of (a) small, subrectangular proepisternum fusing anteromesad with a broad precoxale embracing the anterodorsal margin of fore coxa, (b) subrectangular proepimeron whose posterior part is fused with a minute "proepimeral lobe" (see Discussion) - its shape as in Fig. 8). Proepisternum moderately, proepimeron strongly convex, and outline of both visible in dorsal view. No part of propleuron overlapping the fore coxa.

Prosternum (Fig. 7) dorsally fused with collum and precoxale, broadly and shortly triangularly produced poste$\mathrm{rad}$, the apex of triangular projection delimited, otherwise without specialized features. Proxyphus formed by a slightly sclerotized, large lingulate ental sclerite, reaching the posterior margin of prothorax, and covered by subcontiguous fore coxae. Fore acetabula enormous, contiguous, occupying the whole posterior part of ventral prothoracic area, only entally subdivided by proxyphus.

Pterothorax (Figs 15-16). Mesonotum formed by (a) very short, strip-shaped prescutum; (b) pair of prealar sclerites situated in front of forewings, laterad to anterior margin of scuto-scutellum, (c) large and not subdivided scuto-scutellum delimited from prescutum by a conspicuous transverse bisinuate sulcus; scutal part with parapsidal sulci forming a closed, broad U-shaped area; scutellar part of a modal shape, with a pair of large, shallow proximal pits, its lateral sides moderately concave, apex produced as a rounded mucro; forewing grooves well developed; (d) broadly U-shaped mesopostnotum with posterolateral inflection points subangular.

Metanotum medially about as long as mesopostnotum, simple, forming a band along the latter, posterior margin convex, medially slightly produced posterad.

Mesopleuron. Enormous precoxale fused with both the eusternum and mesepisternum. Pleural sulcus moderately diagonal, followed by a small mesepimeron.

Mesosternum with a large presternite, situated within the emargination of eusternum and surrounded by a membrane; eusternum large and strongly convex, simple anterior margin emarginate, posterior two thirds with linear, percurrent, impressed median, posterior mesosternal margin largely convex, shortly emarginate at the termination of the median.

Metapleuron with a narrow precoxale fully fused with metepisternum; pleural sulcus strongly diagonal, simple metepimeron not reaching the level of metacoxal articulation.

Metasternum small, convex, posterior margin rounded, central part with linear, impressed median.

Mesacetabula and metacetabula not contiguous, situated posterad to their respective sterna, encroaching onto the regions of metathorax (partly) and abdominal ventrites 1 and 2 (fully), respectively.

Trochantines (not illustrated). Trochantine 1 present as a small triangular sclerite in proacetabular membrane in front of dorsal articulation of procoxa, devoid of contact either with body wall or coxa (tentative). Trochantine 2 present as a narrow, crescent-shape sclerite in mesacetabular membrane in front of anterodorsal edge of mesocoxa, devoid of contact either with body wall or coxa. Trochantine 3 situated in metacetabulum as a high, subvertical moderately bent subcrescent-shaped sclerite, possibly contacting both the metepisternum and metacoxa.

Mesothoracic spiracles situated ventrolaterally in the intersegmental pro-mesothoracic membrane; metathoracic 

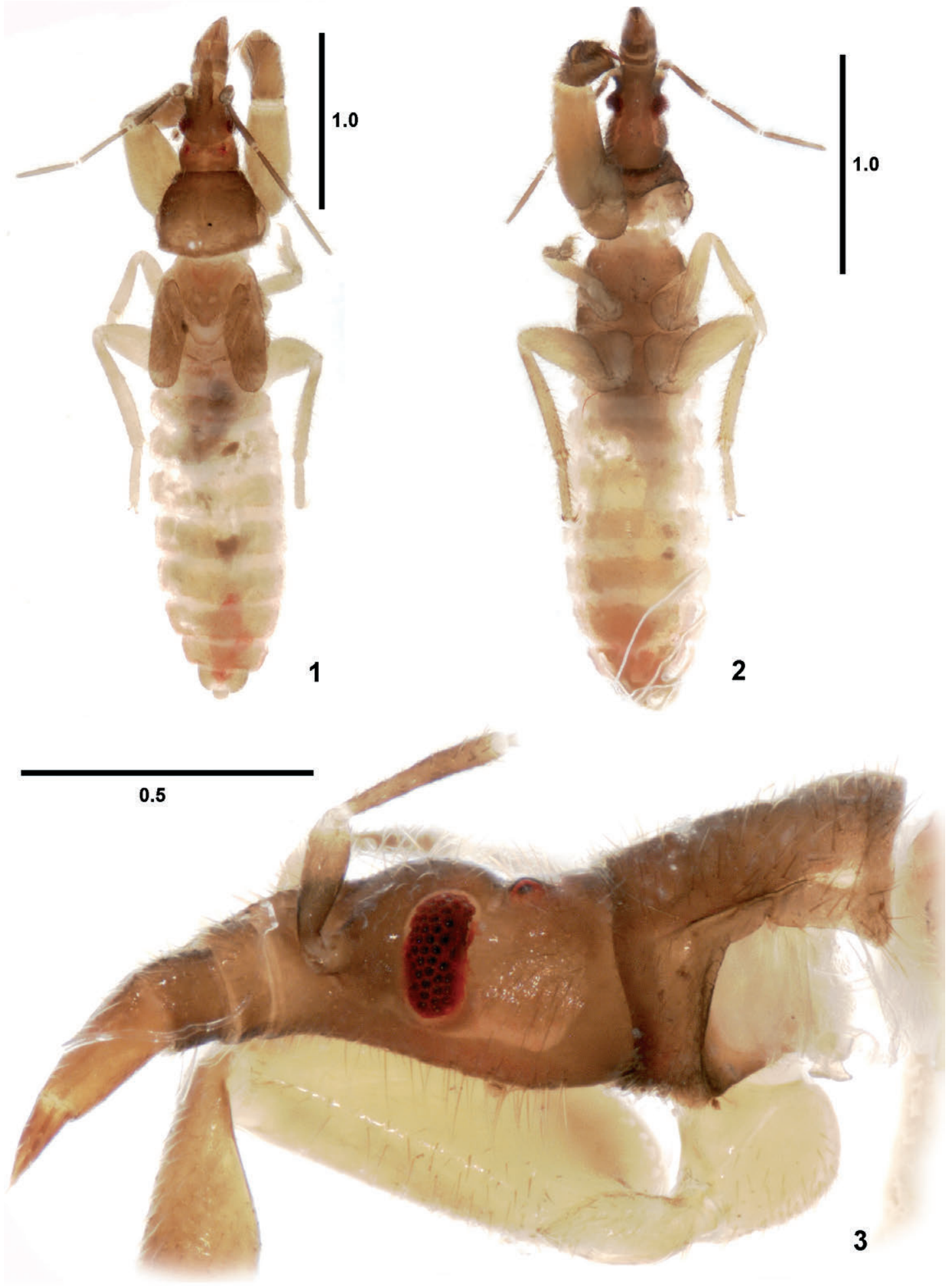

Figs 1-3. Ulugurocoris grebennikovi gen. et sp. n., holotype female. 1 - total dorsal view; 2 - total ventral view; 3 - head and pronotum in left lateral view (left fore leg removed). Scale bars in $\mathrm{mm}$.

spiracles situated at the anterior margin of metepisternum, small, elongate, but not crevice-shaped (observations on spiracles tentative).

Forewings (Fig. 6) micropterous, articulated, narrowly oval, apex rounded, reaching abdominal intersegmental sulcus I-II, leaving the medial parts of pteronotum exposed. Remigium and clavus distinctly separated by claval fracture reaching the ambient vein. Venation reduced, in proximal part of wing present, in distal part fusing and forming a distal sclerotized area. Costal fracture, anchor and hypocostal lamina missing. Marginal and costal setae in one row only; four strikingly longer upstanding setae along costal margin. 
Hindwings membranous, narrowly elliptical, without venation, reaching almost the apex of forewing.

Fore legs thick (Fig. 9). Fore coxae nearly contiguous, strikingly high, in situ much exceeding the ventral side of the body, their vertical diameter longer than that of the body. Trochanter elongate, slender in comparison with large coxa, femur robust, conspicuously convex dorsally. Anterior face of the apex of tibia with two short projections, with a group of three thick spines each (Figs 11-12, 17). Ventral group formed by three conical, differently long spines, all inserted at the same level, but of a different length; dorsal group formed by one (ventral) conical spine and two semicircular, plate-shaped spines. Fore tarsus distally with two conspicuous spines on anterior face, the proximal one spiniform, the apical one plate-shaped (Figs 10, 17). Anterior claw much longer than posterior one.

Middle and hind legs. Hind legs (Fig. 14) much longer than middle legs (Fig. 13). Middle coxae distinctly separated, hind coxae subcontiguous, mesal margins of both middle and hind coxae provided with dark, strongly prominent low tubercles causing their crenulated appearance. Apex of middle tibia with one (anterior) bristle comb composed of 5 setae and group of three strong setae on ventral apex (Fig. 18), distal half of ventral face of tibia with subspiniform setae, stronger than setae on its dorsal and lateral faces. Apex of hind tibia without bristle comb, with three strong setae on ventral apex, surrounded on lateral apices with more slender and shorter setae. Basitarsus (= first tarsal segment) of both middle and hind tibiae with a very short dorsal edge, hardly visible in dorsal view; distitarsus (= second tarsal segment) long. Anterior claws shorter than posterior ones.

Abdomen narrowly oval, pointed, little sclerotized. Long intersegmental membranes between all the segments except VII-IX; no segment telescoped.

Dorsites I and II mutually independent, their sclerites not fused.

Ventrites I and II mutually independent, very long, their joint region stretching from the apex of metasternum over the posterior margins of hind trochanters when the legs are in resting position.

Segments II-VIII each basically composed of a stripshaped dorsal mediotergite, bulging laterotergal tubercles; each tubercle bearing a distinctly sclerotized dorsal laterotergite separated by spiracle-bearing laterotergal membrane from less distinctly delimited and less sclerotized ventral laterotergite, percurrent laterosternal membrane and sternum. Laterotergal tubercle (or the corresponding serial area) always laterally rounded; an abdominal edge (connexival line) only developed on segment VIII. The spiracle-bearing area situated always lateroventrally.

The degree of individuality of the abdominal elements is different on individual segments (Table 1).

Comments on individual abdominal segments. Ventral part of segment I unusually long, occupying all the space between metacoxae. The opening of the mediotergal larval gland formed by a simple, short and narrow trans-
TABLE 1. Architecture of the individual abdominal segments of Ulugurocoris grebennikovi gen. et sp.n.

\begin{tabular}{|c|c|}
\hline $\begin{array}{l}\text { Abdominal } \\
\text { segment }\end{array}$ & Architecture \\
\hline I & MTG - VLTG, Sp - ? - S (tentatively) \\
\hline II & MTG - LT (DLTG $-\mathrm{mt}, \mathrm{Sp}-\mathrm{VLTG})-\mathrm{ms}-\mathrm{S}$ \\
\hline III & MTG - LT (DLTG $-m t, S p-$ VLTG $)-m s-S$ \\
\hline IV & MTG - LT (DLTG $-\mathrm{mt}, \mathrm{Sp}-\mathrm{VLTG})-\mathrm{ms}-\mathrm{S}$ \\
\hline $\mathrm{V}$ & MTG + LT (DLTG, Sp \& VLTG) $-\mathrm{ms}-\mathrm{S}$ \\
\hline VI & $\mathrm{MTG}+(\mathrm{DLTG}, \mathrm{Sp} \& \mathrm{VLTG})-\mathrm{ms}-\mathrm{S}$ \\
\hline VII & (MTG \& DLTG, Sp \& VLTG) $-\mathrm{ms}-\mathrm{S}$ \\
\hline VIII & $\begin{array}{c}\text { (MTG \& DLTG, Sp \& VLTG) }-\mathrm{ms}-(\mathrm{h}) \mathrm{S}+\mathrm{SG} \\
- \text { ovipositor }\end{array}$ \\
\hline IX & MTG - membrane - (DLTG \& VLTG \& hS) \\
\hline
\end{tabular}

Abbreviations: DLTG - dorsal laterotergite; (h)S or hS sternum indicatively or distinctly subdivided in hemisternites, respectively; LT - laterotergal tubercle; ms - laterosternal membrane; $\mathrm{mt}$ - laterotergal membrane; MTG - mediotergite; $\mathrm{Sp}$ - spiracle (associated with the symbol of the pertinent area); $\mathrm{S}$ - sternum; VLTG - ventral laterotergite. Explanations: $\mathrm{x}+\mathrm{y}$ $=\mathrm{x}$ and $\mathrm{y}$ distinct, but not separated by a membrane; $(\mathrm{x} \& \mathrm{y})=$ $\mathrm{x}$ and $\mathrm{y}$ indistinguishable, forming a single entity.

verse subarcuate slit situated on mediotergite IV closely posterad to intersegmental membrane III-IV. The connexival edge is only developed along external border of DLTG VIII, just below spiracle.

Terminalia. Segment VIII (see Table 1). Dorsal and lateral parts without modifications; spiracles larger and more distinct than those on pregenital segments. Anterior margin of sternum VIII deeply excised, mid-part somewhat desclerotized, posterior margin produced as a distinctly delimited, apically rounded, cone-shaped subgenital plate exceeding posteriorly the dorsite VIII.

Ovipositor (the description open to reinterpretation) forming the tip of abdomen, arising from above the subgenital plate, horizontal, protruding over the dorsally receding segment IX, situated more ventrally than the latter; the independent bases of the left and right halves not fused with ventrite VIII nor with subgenital plate. Left and right parts possibly asymmetrical, each formed by a pair of spikes and a single semi-sclerotized sheaths enveloping the spikes (for details see the species description). Shape as illustrated (Figs 20-21).

Segment IX (see Table 1) shaped as a dorso-caudally raised short tube, ventrally distinctly subdivided into hemisternites by a linear median sulcus. The posterodorsal margin of dorsite IX broadly emarginate and harbouring a strongly sclerotized segment $\mathrm{X}$, triangle-shaped and in lateral view dorsally sinuate, carrying a ventral, small, membranous segment XI.

Spermatheca basically as in Fig. 19 (see species description).

Abdominal spiracles (see Table 1). Present on segments I-VIII, either in the membrane separating dorsal and ventral laterotergites, or in the ventral-most part of the dorsal [sic!] laterotergite or in a region corresponding to the latter. 


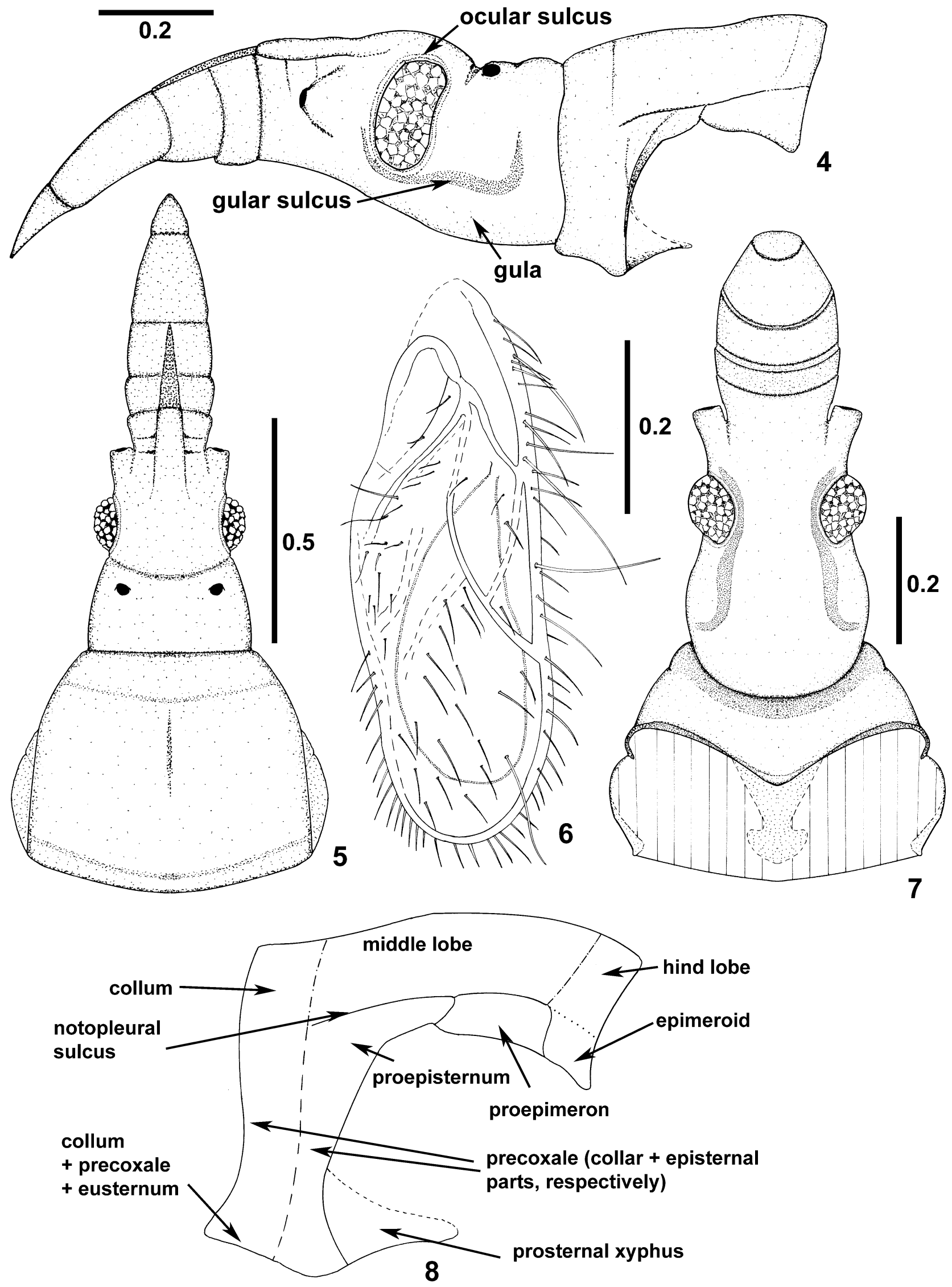

Figs 4-8. Ulugurocoris grebennikovi gen. et sp. n., holotype female. 4 - head and pronotum in lateral view; 5 - head and pronotum in dorsal view; 6 - right forewing (assessment of venation only tentative) and outline of the shape and position of the hindwing; 7 - head and pronotum in ventral view; 8 - prothorax in lateral view, scheme. Scale bars in $\mathrm{mm}$. 


\section{Differential diagnosis.}

The genus Ulugurocoris belongs to the subfamily Aenictopecheinae that includes 6 genera (Štys, 1989, 1995; Wygodzinsky \& Schmidt, 1991; for distribution see Discussion). Ulugurocoris differs from the others by (1) combination of presence of a single bristle comb on middle tibia and absence of the bristle combs on the hind tibia (bristle combs missing in Australostolus Štys, 1980, Boreostolus Wygodzinsky \& Štys, 1970, Gamostolus Bergroth, 1927 and Lomagostus Villiers, 1958; one long, continuous comb, not divided between anterior and posterior one occurring on middle and hind tibiae in Tornocrusus Kritsky, 1977; middle tibia of Aenictopechys Breddin, 1905 provided with one (posterior) comb, hind tibia with two combs) and (2) subgenital plate VIII distinctly delimited from ventrite VIII (unique). Furthermore, it differs from Aenictopechys by only slightly prominent apicitibial process on fore tibia (the latter very long, uniquely shaped in Aenictopechys) and distinctly developed ovipositor (extremely reduced or missing in Aenictopechys); from Gamostolus and Boreostolus by strongly transverse posterior lobe of head (not, or only inconspicuously transverse in Boreostolus and Gamosto$l u s$ ) and minute proepisterna and proepimera (large in Boreostolus and Gamostolus); from Australostolus, Gamostolus and Tornocrusus by fore tarsal armature composed of two spines only (four in above mentioned genera); from Lomagostus by large meso- and metatrochanters and coxae (much smaller in Lomagostus). Ulugurocoris also differs from all known aenictopecheine genera with the exception of Boreostolus by its microptery. Macropterous, brachypterous and micropterous forms occur in Boreostolus americanus Wygodzinsky \& Štys, 1970, only micropterous forms of B. sikhotalinensis Wygodzinsky \& Štys, 1970 are known.

Etymology. Derived from Ulugur-u Mts in Tanzania and -coris (Greek, meaning bug); gender is masculine.

\section{Ulugurocoris grebennikovi sp. $\mathbf{n}$.}

(Figs 1-21)

Type material. Holotype: micropterous female: "Tanzania, Uluguru Mts. / at Budunki vil. / S07 $00^{\prime} 15^{\prime \prime}$ E037 $37^{\prime} 50^{\prime \prime}$ 24.xi.2010, $1848 \mathrm{~m}$, / sifting 24, V. Grebennikov". Holotype preserved in alcohol, left fore leg dry mounted separately; deposited in the collection of the Moravian Museum in Brno. One micropterous female paratype: same data as holotype. Specimen dissected, abdomen, pterothorax and right middle and hind legs preserved in glycerol; rest of the body preserved in alcohol. Left fore, middle and hind legs gold-plated for SEM study. Paratype deposited in the Pavel Štys collection, Charles University, Prague.

Other material examined. 2 larvae of fifth instar (most probably male and female), one larva of fourth (?) instar, same data as holotype; all larvae excluded from the type series (to be described in a separate paper).

Measurements. Holotype (in $\mathrm{mm}$ ). Total body length 3.71. Head. Total length -0.53 ; posterior lobe, medial length 0.17 , width -0.37 ; distance of eye to apex of antennifer -0.14 ; diatone (maximum width across eyes) -0.38 ; dorsal synthlipsis (minimum interocular distance) -0.24 ; ventral synthlipsis 0.18 ; eye, length -0.16 ; distance of dorsal margin of eye to vertex in lateral view - 0.04; distance of ventral margin of eye to ventral-most part of head in lateral view -0.07 ; interocellar distance -0.20 , distance ocellus - lateral margin of posterior lobe of head -0.07 . Labium. Total length -0.60 ; segment I, length -0.09 ; segment II, length -0.11 ; segment III, length 0.27 ; segment IV, length -0.13 . Antenna. Total length -1.38 ; segment I, length -0.22 ; segment II, length -0.33 ; segment III, length -0.38 ; segment IV, length -0.44 . Pronotum. Total length (maximum) -0.51 ; collum, length -0.13 ; middle lobe, width -0.62 ; hindlobe, width -0.62 . Fore leg. Femur, length 0.80 , width (maximum) -0.33 ; tibia, length -0.56 , width (maximum) -0.19 ; tarsus, length -0.23 , width (maximum) 0.11 . Middle leg. Femur, length -0.60 , width (maximum) 0.13; tibia, length -0.44 , width (maximum) -0.09 . Hind leg. Femur, length -0.78 , width (maximum) -0.22 ; tibia, length 0.89 , width (maximum) -0.11 .

\section{Description}

Coloration generally brown to yellowish, abdomen rose (probably bleached in alcohol and originally red), legs yellowish.

Head (Figs 4-5, 7). Dorsum and venter covered with long erect setae, lateral parts with semi-erect setae directed antero-ventrally. Ratio distance from anterior margin of eye to apex of antennifer / eye length 0.88 . Dorsal ocular index 3.43, ventral ocular index 1.8. Posterior lobe rounded laterally, ratio of maximum width to median length 2.18 .

Antennae with two types of setae; first semi-erect, directed anteriorly, of sub-equal length as segment diameter, occurring on all segments. Second type long, sparsely distributed, conspicuously erect, much longer than segment diameter, occurring only on segments II-IV. Segment I widest, widening apically, segment II more slender than segment I, slightly widening apically, segments III and IV thinner, nearly terete.

Labium densely covered with long, semi-erect setae approximately. Segment I narrowly ring-shaped, segment II broadly ring-shaped, segment III longest, narrowing apically.

Prothorax. Pronotum, lateral and ventral parts of prothorax uniformly covered with semi-erect setae directed posterad, setae somewhat longer and more erect on collum, and clustered at the "proepimeral lobe". Pronotum wider than long, ratio 1.22 .

Pterothorax. The visible parts with semi-erect (directed posterad) to erect setae. Forewings dorsally densely covered with semi-erect setae mixed with very long, erect setae.

Forelegs. Posterior, dorsal and ventral faces of coxa, trochanter, femur, tibia and all faces of tarsus densely covered with long erect setae. Vestiture on posterior and ventral faces of femur, tibia and tarsus mixed with very long trichobothrium-like setae. Anterior face of coxa bare; anterior face of trochanter with semi-erect setae, anterior face of femur sparsely covered with short semierect setae (less than thirty in total); anterior face of tibia with numerous, semi-erect to appressed setae, becoming shorter and denser apically. Bristle comb on anterior apex of tibia long (Fig. 17), composed of approximately 38 setae. 

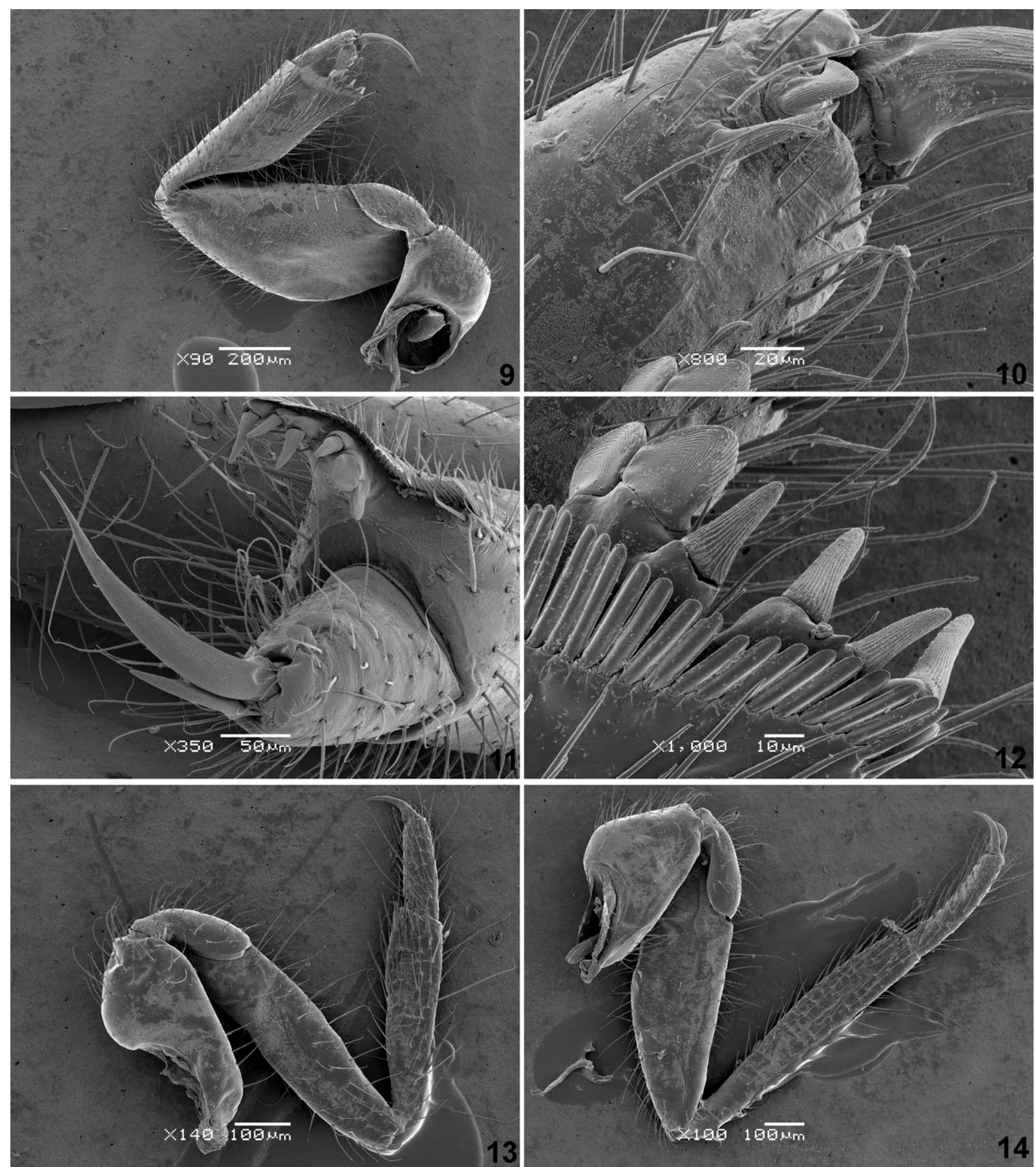

Figs 9-14. Ulugurocoris grebennikovi gen. et sp. n., paratype female. 9 - right foreleg in anterior view; 10 - right fore tarsus in ventral view; 11 - right fore tarsus and apex of fore tibia in dorsal view; 12 - right fore tibial armature in anterior view; 13 - left middle leg in posterior view; 14 - left hind leg in posterior view.

Femur strikingly wide, ventral outline straight, dorsal outline strongly convex (Fig. 9); ratio of its length to its maximum width 2.42 . Tibia proximally thin from lateral view, contrasting with wide distal half, ratio its length to maximum width 2.95. Tarsus about twice as long as wide, ratio 2.09. Length of the anterior claw sub-equal to that of tarsus.
Middle and hind legs. Posterior face of middle coxa nearly bare, with few (less than 15) setae distally. Posterior face of hind coxa and hind femur bare. Other faces of middle and hind legs covered with erect to semi-erect setae (coxae, trochanters, femora vs. tibiae, respectively), intermixed with long, sparsely distributed trichobothriumlike setae (anterior faces of coxae, femora, tibiae and tarsi; dorsal faces of femora, tibiae and tarsi, and ventral 


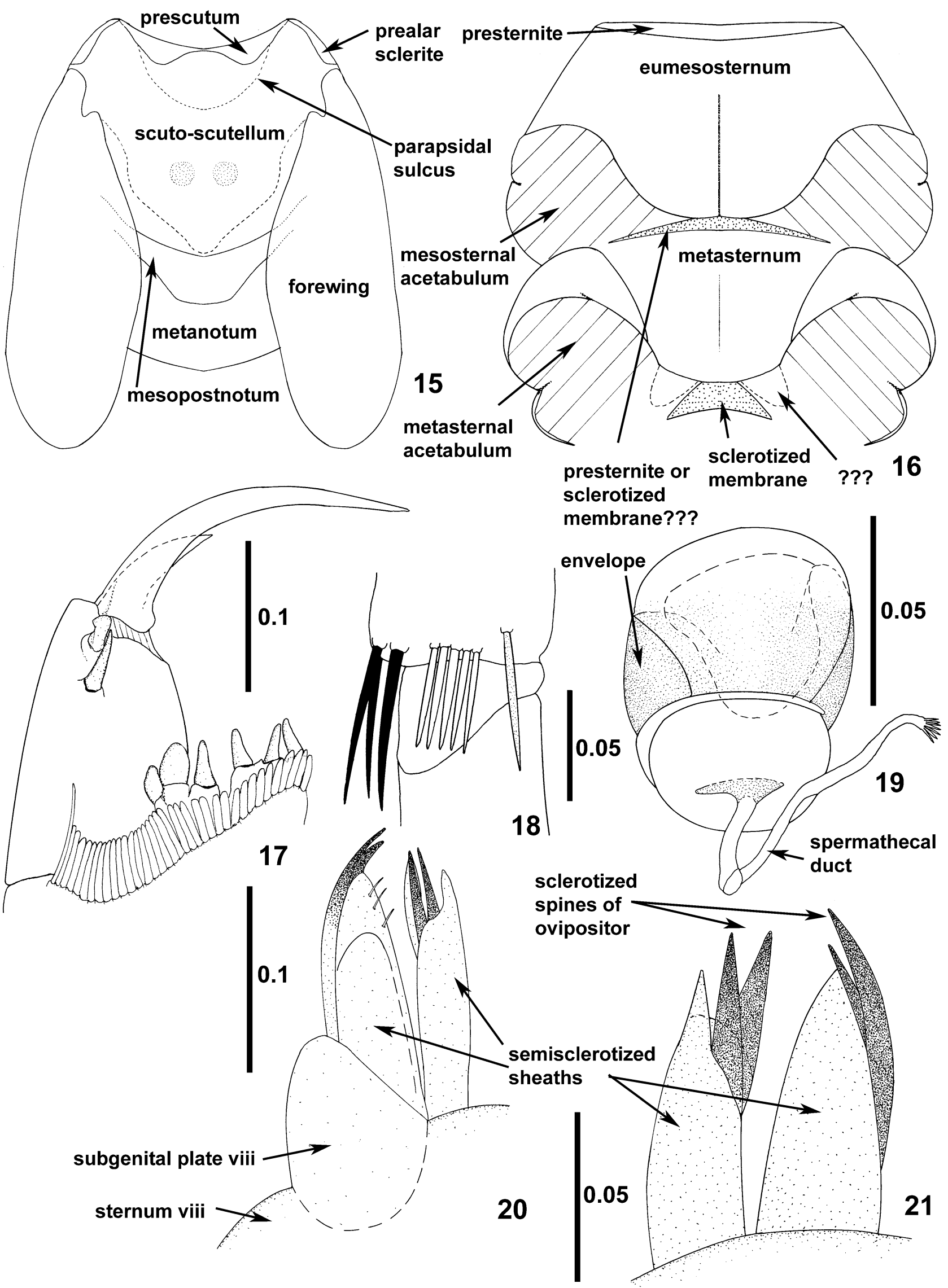

Figs 15-21. Ulugurocoris grebennikovi gen. et sp. n., paratype female. 15 - pterothorax in dorsal view; 16 - pterothorax in ventral view; 17 - fore tarsus and apex of fore tibia in antero-ventral view; 18 - apex of right middle tibia in anterior view; 19 - spermatheca (reconstruction); 20 - subgenital plate of sternum viii and ovipositor, subventral view, ovipositor shifted to the right (glycerol mount); 21 - ovipositor, dorsal view (glycerol mount). 15-16 schemes; 17-21 scale bars in mm. 
faces of trochanters, femora and tarsi). Both middle and hind trochanters with anterior and posterior trochanteral organs.

Middle tibia very short, about half the length of hind tibia. Middle femur symmetrical in lateral view, dorsal and ventral outlines almost straight; longer than middle tibia, ratio 1.37. Hind femur with convex dorsal outline, ventral outline straight, shorter than hind tibia, ratio 0.88 . Hind tibia slightly curved, hind tarsus very long.

Spermatheca (Fig. 19) formed by two large sclerotized bulbs (the proximal one smaller; the distal one larger and provided with a large, distal, broadly rounded, tongueshaped evagination tipped over towards the proximal bulb) connected by a narrow sclerotized ring (two rings?) and a lateral membranous "envelope". No apical cap or proximal flanges. Ductus spermathecae simple, with a funnel-shaped entry to the proximal bulb and a fimbriate termination. Distal part of the spermatheca situated in abdominal segment VII, proximal part in VIII; the fimbriate opening of ductus spermathecae asymmetrically in the right proximal third of VIII.

Eggs. Abdominal cavity nearly filled up by one large proximal and two smaller distal oval eggs. The length of the large egg about equal to length of two and half abdominal segments.

Habitat and collecting method. Sifted and subsequently extracted by Winkler apparatus from leaf litter in mountain rain forest, about $1800 \mathrm{~m}$ altitude.

Distribution. Tanzania, south-east part of Eastern Arc Mountains, Uluguru Mountains.

\section{DISCUSSION}

\section{Anatomy of Ulugurocoris}

There is no truly comparative morphological study of Aenictopecheidae available. We stress the features of general importance; some of them may be shared by other enicocephalomorphans.

Trichobothria. The mere presence of $3+3$ cephalic trichobothria (4+4 in the Gerridae) is not an autapomorphy of Gerromorpha as often implied (Andersen, 1982; Schuh, 1975; Schuh \& Slater, 1995); rather their insertion in deep socket is autapomorphic as noticed by the same authors. Presence of $3+3$ cephalic trichobothria (or a homologous set of similarly positioned sensory setae, precursor of the trichobothria) with basically identical topography is an autapomorphy of the Heteroptera as already suggested by Cobben (1978). The cephalic trichobothria occur in the Enicocephalomorpha and Dipsocoromorpha s. lat. (P. Štys, unpubl.) and sporadically among Panheteroptera, though often are difficult to distinguish from other macrotrichia, reduced or secondarily absent. The nature of trichobothrium-like setae in basal infraorders is under our investigation.

Head. Several features of Ulugurocoris are unusual among the Heteroptera:

(a) Paired gular sulci are situated in close proximity to complete, circular ocular sulci. The anterior parts of gular sulci parallel the ocular sulci, continuing onto the posteroventral face of head, turning dorsad far behind eyes and terminating blindly on the lateral part of the posterior lobe (Figs 4, 7). Absence of any kind of remnants of ecdysial sulci on the cephalic dorsum suggests that the gular sulci, whatever their homology is, perform this function. As far as we know the ecdysial sulci are dorsal with diverse courses relative to the eyes in the Enicocephalidae (Štys \& Baňař, unpubl.).

(b) Presence of large eyes and well developed ocelli in spite of micropterism is unusual; their reduction would be expected in the Enicocephalomorpha.

(c) The posterior lobe of head is only demarcated on the dorsum, the postocular constriction is not indicated on the venter. There is no indication of a neck (postocciput?), and its absence may represent a symplesiomorphy shared with non-heteropteran Hemiptera. The majority of Heteroptera possess a well demarcated neck that may be permanently or temporarily telescoped within the prothorax.

Pronotum. The architecture of pronotum in Ulugurocoris clearly shows that the three lobes are present even in micropterous morphs of the Aenictopecheidae. The contrary statements in the literature concerning the Aenictopecheidae ("posterior lobe absent") are erroneous. Here, the posterior lobe of pronotum is formed by a not externally demarcated posterior strip of the pronotum. Its distinctness is suggested by its general appearance (in alcohol-preserved specimen) and shown by its association with the minute "proepimeral lobe" (see below) formed by that posterolateral part of prothoracic wall situated more ventrally than the notopleural sulcus.

We have noticed several times (e.g., Štys \& Baňař, 2006 b) that the so called "proepimeral lobe" of the Enicocephalomorpha and other Heteroptera is a part of the posterior lobe of the pronotum, and that only the topography and a frequent fusion associate it with the pleural proepimeron. We suggest to discontinue the usage of the definitely inappropriate term "proepimeral lobe" and to call it epimeroid in all the Heteroptera. This structure concerns the architecture of prothorax only, hence the obvious alternative term "proepimeroid" is overly pedantic.

Propleuron. In addition to precoxale (of composed origin), the lateral wall of prothorax is formed by only two sclerites not overlapping the fore coxa. These sclerites may be identical either with (a) episternum and epimeron, or (b) anterior and posterior prosupracoxalia, or (c) products of fusions of (a) and (b) that are indistinguishable as to their original components. The exaggerated size of coxa is associated with reduction of the lateral thoracic wall (pleuron) ventrad to the notopleural sulcus (universally present in the Aenictopecheidae; a desirable review of its occurrence in Heteroptera is not available). This reduction might have been structurally achieved either at the expense of episternum and epimeron or at the expense of their supracoxacoxalia.

Pterothorax. The architecture of pterothorax in females is affected by microptery; that of the potentially macropterous males would be greatly different. Presence 
of micropterous forewings combined with relatively well developed hindwings seems to be unknown in the Enicocephalomorpha. However, the hindwings might have been overlooked in other species. The length of the forewing lobes of male larva suggests that the males of Ulugurocoris grebennikovi is probably macropterous.

Trochanteral organs on fore legs have been studied by us (Štys, 1986; Baňař \& Štys, 2006; Štys \& Baňař, 2006a, b, 2007; Baňař, 2008) in several genera of the Enicocephalidae. They are very similar to those occurring in the Aenictopecheidae (Ulugurocoris grebennikovi) and seem to be universally present in the Enicocephalomorpha.

Shape of the ovipositor suggests potential insertion of an egg in a plant tissue. However, the large size of the egg makes this hypothesis improbable and we can consider a function performed during mating, possibly breaking the spermatophore. Alas, no direct observations of mating behaviour of any aenictopecheid are available.

\section{Taxonomy and distribution}

The subfamily Aenictopecheinae. Though the higher classification of the Enicocephalomorpha was elaborated by Štys $(1989,1995)$ the conception of the family Aenictopecheidae has to be amended, both as to its diagnostic characters, and hierarchy of taxa. The Aenictopecheidae are defined mostly by plesiomorphies (in terms of Enicocephalomorpha, Heteroptera and Hemiptera). For that reason the conception was criticized by Grimaldi \& Engel (2005), but their suggestion to combine Aenictopecheidae and Enicocephalidae in a single family (identical as to the inclusion with the Enicocephalomorpha) was not helpful, since the problem would have been only relegated to lower categorical level of the Linnaean hierarchy. For formulation of a cladogenetic hypothesis and establishment of a phylogenetic classification of the Enicocephalomorpha we need to complete several taxonomicmorphological studies of critical and mainly undescribed taxa from the Eastern Hemisphere. For that reason we outline here only the classification and distribution of the only cosmopolitan and undoubtedly monophyletic nominotypical subfamily Aenictopecheinae. The other subfamilies of the Aenictopecheidae [Nymphocorinae - New Zealand and Tasmania, Maoristolinae - New Zealand, Murphyanellinae (monophyly doubtful) - Malesia] probably merit family ranks.

The Aenictopecheinae are clearly delimited by combination of the following non-polarized characters:

- posterior lobe of pronotum indistinct and reduced in size;

- fore legs raptorial;

- tarsal formula of adults 1-2-2;

- forewings of macropters with costal fracture;

- forewings of macropters without RP;

- phallus external and non-erectible;

- parameres mobile, associated with phallic base, never plate-shaped;

- ovipositor distinctly present (except for Aenictopechys), spermatheca present;
- opening of adult dorso-abdominal gland (unpaired on segment IV) and associated structures simple;

- forewing pads of last larval instar of macropters mutually contiguous.

Distribution of aenictopecheine genera. The presently known distribution is primarily circumtropical with isolated genera occurring in temperate regions:

- continental Australia - Australostolus - 1 species (A. monteithi Štys, 1980);

- Great Sundas - Aenictopechys - 1 species (A. necopinatus Breddin, 1905; more to be described);

- continental Oriental Region - one or more new species of Aenictopechys and new genera and species to be described;

- Madagascar - Lomagostus - 1 species (L. jeanneli Villiers, 1958), and new genera and species to be described;

- Afrotropis - Ulugurocoris - 1 species (U. grebennikovi), presently described from Tanzania;

- Patagonia s. lat. - Gamostolus - 1 species [G. subantarcticus (Berg, 1883)];

- Northern Neotropical Cordilleras (Colombia and Venezuela) - occurrence of one new species Gamostolus or new genus and species indicated by presence of larvae (Wygodzinsky \& Schmidt, 1991);

- Neotropis - Tornocrusus - 9 species, several new species to be described;

- Nearctis - W USA: Colorado, Oregon, Washington Boreostolus - 1 species (B. americanus Wygodzinsky \& Štys, 1970);

- Palaearctis: Far East of Russia from Vladivostok to Magadan (Kerzhner, 1988) - Boreostolus - 1 species (B. sikhotalinensis Wygodzinsky \& Štys, 1970).

"To be described" refers in all cases to Baňař and Štys, unpublished. It is also possible that some of the undescribed taxa from New Zealand belong here. It is remarkable that so far the ranges of all the genera are allopatric (with the possible exception of an undescribed taxon from Northern Neotropical Cordilleras and Tornocrusus).

Since the locality in which Ulugurocoris has been discovered belongs to an extremely biogeographically important and little known Afrotropical area, we provide below basic information on the Eastern Arc Mountains.

Eastern Arc Mountains. The Eastern Arc Mountains is a biogeographical concept that appeared only recently (Lovett, 1985) and is used for a chain of 13 mountain blocks uplifted during Miocene (Lovett, 1993) and spreading from south Kenya (Taita Hills) across eastern Tanzania. It is formed by thirteen separate mountain blocks covered by about $3300 \mathrm{~km}^{2}$ of sub-montane, montane and upper montane forest (Burgess et al., 2007) with a variety of biotopes, all being under direct climatic influence of the Indian Ocean. The remaining forest is highly fragmented by human activity and fire, its patches are small and represent less than a quarter of the originally continuously forested area (Newmark, 1998).

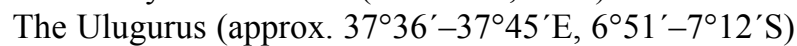
belong to the three most important Eastern Arc blocks, and are the highest $(2635 \mathrm{~m})$. Their forests are situated at 
altitudes of 300-2400 m (mean altitude $1350 \mathrm{~m}$ ), occupy nearly $1500 \mathrm{~km}^{2}$, and the area is characterized by MAT $24.6^{\circ} \mathrm{C}$, and MAP reaches $1615 \mathrm{~mm}$ (data from Yessoufou et al., 2012).

Burgess et al. (2007) provided a general survey of the Eastern Arc, and concluded that these mountains "rank among the most important areas of the world for the conservation of endemic birds ..., endemic plants..., and a combined set of taxonomic groups". Both the absolute and relative degree of endemism is amazing: at least 96 tetrapod vertebrate species (particularly birds) are endemic, further 71 species are near endemic, at least 800 vascular plants are endemic. The situation is similar for all other groups comprehensively studied, such as mosses, linyphiid spiders, harvestmen, millipedes, Odonata, carabid beetles and Lepidoptera.

Jetz et al. (2004) concluded that the Eastern Arc posses significantly more endemic species than expected by chance, topography and environment. Burgess et al. (2007) have shown that the Eastern Arc is not only a centre of speciation but also an area where species avoid extinction. The evidence is genetic and phylogeographic, and is supported by occurrence of extant members of basal lineages of taxa extinct elsewhere. Some taxa of the Eastern Arc have their closest relatives in Madagascar (molluscs - Emberton et al., 1997; vascular plants Lovett \& Friis, 1996; bryophytes - Pócs, 1998). Burgess et al. (2007) concluded that all the indirect evidence suggests that the reason for survival of "ancient taxa" is that the area has been less subjected to intensive climatic change.

ACKNOWLEDGEMENTS. We would like to thank our friend V.V. Grebennikov (Ottawa) for his gift of this interesting material. We also thank P. Kment (Prague) and D. Rédei (Budapest) for review and comments on the manuscript. This paper appears through financial support provided to the Moravian Museum by the Ministry of Culture of the Czech Republic as part of its long-term conceptual development programme for research institutions (ref. MK000094862) and Grant of the Faculty of Science of Charles University in Prague (SVV-2013-267 201) (PB).

\section{REFERENCES}

ANDERSEn N.M. 1982: The Semiaquatic Bugs (Hemiptera: Gerromorpha): Phylogeny, Adaptations, Biogeography, and Classification. Entomonograph 13. Scandinavian Science Press, Klampenborg, $455 \mathrm{pp}$.

BAŇǍ̆ P. 2008: A new species of Systelloderes (Hemiptera: Heteroptera: Enicocephalidae) from South Africa. - Acta Entomol. Mus. Nat. Pragae 48: 233-240.

BAŇǍ̆ P. \& ŠTYs P. 2006: A new species of Pseudohenschiella (Heteroptera: Enicocephalidae) from Madagascar. - Acta Entomol. Mus. Nat. Pragae 46: 7-14.

Burgess N.D., Butynski T.M., Cordeiro N.J., Doggart N.H., Fjeldsa J., Howell K.M., Kilahama F.B., Loader S.P., Lovett J.C., Mbilinyi B., Menegon M., Moyer D.C., Nashanda E., Perkin A., Rovero F., Stanley W.T. \& Stuart S.N. 2007: The biological importance of the Eastern Arc Mountains of Tanzania and Kenya. - Biol. Conserv. 134: 209-231.
CobBen R.H. 1978: Evolutionary Trends in Heteroptera. Part 2. Mouthpart-structures and Feeding Strategies. Mededlingen Landbouwhogeschool 78-5. H. Veeman, Wageningen, 407 pp.

Emberton K.C., Pearce T.A., Kasigwa P., Tattersfield P. \& HABIBU Z. 1997: High diversity and regional endemism in land snails of eastern Tanzania. - Biodiv. Conserv. 6: 1123-1136.

Grimaldi D. \& Engel M.S. 2005: Evolution of the Insects. Cambridge University Press, Cambridge, xiii +755 pp.

Jetz W., Rahbek C. \& Colwell R.K. 2004: The coincidence of rarity and richness and the potential signature of history in centers of endemism. - Ecol. Letters 7: 1180-1191.

KERZHNER I.M. 1988: Infraorder Enicocephalomorpha. In Ler P.A. (ed.): Key to Indentification of Insects of the Far East of USSR in Five Volumes. Vol. 2. Nauka, Leningrad, p. 737 [in Russian].

LovetT J.C. 1985: Moist forests of Tanzania. - Swara 8: 8-9.

LovetT J.C. 1993: Eastern Arc moist forest flora. In Lovett J.C. \& Wasser S.K. (eds): Biogeography and Ecology of the Rain Forests of Eastern Africa. Cambridge University Press, Cambridge, pp. 33-57.

LovetT J.C. \& Fris I. 1996: Some patterns of endemism in the tropical north east and eastern African woody flora. In van der Maesen L.J.G., van der Burgt X.M., van Medenbach de Rooy J.M. (eds): The Biodiversity of African Plants. Proceedings XIV $V^{\text {th }}$ AETFAT Congress, 22-27 August 1994, Wageningen, The Netherlands. Kluwer, Dordrecht, pp. 582-601.

Newmark W.D. 1998: Forest area, fragmentation, and loss in the Eastern Arc Mountains: implications for the conservation of biological diversity. - J. East Afr. Nat. Hist. 87: 29-36.

Pócs T. 1998: Bryophyte diversity along the Eastern Arc. $-J$. East Afr. Nat. Hist. 87: 75-84.

SсHUH R.T. 1975: The structure, distribution, and taxonomic importance of trichobothria in the Miridae (Hemiptera). Am. Mus. Nov. 2585: 1-22.

Schun R.T. \& Slater J.A. 1995: True Bugs of the World (Hemiptera: Heteroptera): Classification and Natural History. Cornell University Press, Ithaca and London, $336 \mathrm{pp}$.

ŠTYS P. 1986: A new genus and species of Enicocephalidae from Saudi Arabia (Heteroptera). - Ann. Soc. Entomol. Fr. (N.S.) 22: 255-264.

ŠTYS P. 1989: Phylogenetic systematics of the most primitive true bugs (Heteroptera: Enicocephalomorpha, Dipsocoromorpha). - Práce Slov. Entomol. Spol. SAV 8: 69-85 [in Czech, English abstr.].

ŠTYS P. 1995: Enicocephalomorpha. In Schuh R.T. \& Slater J.A. (eds): True Bugs of the World (Hemiptera: Heteroptera): Classification and Natural History. Cornell University Press, Ithaca and London, pp. 67-73.

ŠTYS P. \& BAŇǍ̆ P. 2006a: New species of Neoncylocotis (Heteroptera: Enicocephalidae) from Ecuador, with some morphological considerations. - Pol. Pis. Entomol. 75: 169-183.

ŠTYS P. \& BAŇǍ̆ P. 2006b: Description of a new genus with larviform females from Mauritius (Heteroptera, Enicocephalidae), with discussion of thoracic and abdominal morphology. In Rabitsch W. (ed.): Hug the bug - For love of true bugs. Festschrift zum 70. Geburtstag von Ernst Heiss. Denisia 19: 681-695.

ŠTYS P. \& BAŇAŘ P. 2007: The first species of Systelloderes (Hemiptera: Heteroptera: Enicocephalidae) from New Caledonia. - Acta Entomol. Mus. Nat. Pragae 47: 3-15.

Wygodzinsky P.W. \& Schmidt K. 1991: Revision of the New World Enicocephalomorpha (Heteroptera). - Bull. Am. Mus. Nat. Hist. 200: 1-265. 
WYGODZINSKY P.W. \& ŠTYS P. 1970: A new genus of aenictopecheinae bugs from the Holarctic (Enicocephalidae, Hemiptera). - Am. Mus. Nov. 2411: 1-17.

Yessoufou K., Daru B.H. \& Davies T.J. 2012: Phylogenetic patterns of extinction risk in the Eastern Arc ecosystems, an
African biodiversity hotspot. - PLoS ONE 7(10): e47082. doi:10.1371/journal.pone.0047082.

Received May 9, 2013; revised and accepted June 13, 2013 